\title{
Políticas públicas educacionais: vozes que emergem no trabalho docente na Educação Infantil
}

\author{
Verônica Belfi Roncetti Paulino a \\ Valdete Côco ${ }^{\text {b }}$
}

\section{Resumo}

Este artigo, decorrente de pesquisa de mestrado, aborda as políticas públicas no campo da Educação Infantil (EI) focalizando a constituição da docência na perspectiva da afirmação da indissociabilidade do educar e cuidar. Discute a questão da presença de diferentes grupos de profissionais docentes atuando com o mesmo grupo de crianças. Sustenta-se no desenvolvimento de pesquisa de abordagem qualitativa de orientação sócio-histórica, com procedimentos metodológicos de observação participante e entrevistas. Os dados sinalizam, no bojo das políticas públicas educacionais, que a constituição da docência na EI interage com um repertório hierárquico oficial composto de aspectos referentes à formação requisitada, atribuições demandadas e delineamento das carreiras, com suas políticas de reconhecimento e valorização, enfraquecendo a perspectiva da indissociabilidade do educar e cuidar nesse campo.

Palavras-chave: Educação infantil. Profissionais docentes. Políticas públicas educacionais.

\section{Introdução}

Abordar a temática da docência na Educação Infantil (EI) e sua relação com o desenvolvimento profissional no contexto da implementação das políticas públicas educacionais implica considerar uma processualidade reconfigurativa das instituições educativas e do trabalho requerido nesse campo (VICENTINI;

\footnotetext{
a Universidade Federal do Espírito Santo - UFES, Grupo de Pesquisa "Formação e Atuação de Educadores" - GRUFAE. Vitória, Espírito Santo, Brasil. Secretaria Municipal de Educação da Prefeitura Municipal de Afonso Cláudio. Afonso Cláudio, Espírito Santo, Brasil.

b Universidade Federal do Espírito Santo - UFES, Centro de Educação, Programa de Pós-Graduação em Educação - PPGE/CE. Grupo de Pesquisa "Formação e Atuação de Educadores" - GRUFAE. Tutora do Programa de Educação Tutorial Conexões de Saberes: Projeto Educação, Ministério da Educação - MEC. Brasília, Distrito Federal, Brasil.
} 
LUGLI, 2009). Tais políticas afetam o sistema educacional por meio de "reformas genéricas que por sua vez repousam na instalação de um conjunto de tecnologias políticas que incidem em novos valores, novas relações e novas subjetividades nas arenas da prática" (BALL, 2001, p. 102). Nesse quadro, destacamos a presença de um "conjunto de tecnologias políticas estabelecidas" por meio de "novas formas de governo e de controle da profissão" (NÓVOA, 2011, p. 20), as quais vêm produzindo, no cenário brasileiro, uma linguagem organizacional, alicerçada em um modelo escolar unificado. Essa perspectiva modelar insta propositivas para a estruturação física das instituições, a organização do atendimento, a distribuição dos investimentos, a dinâmica de trabalho empreendido, entre outras mudanças (OLIVEIRA, 2011).

Para tratarmos da docência na EI, assinalamos que, de maneira geral, essa perspectiva modelar para as instituições educativas é alicerçada em indicativos provenientes do atendimento no Ensino Fundamental, num contexto em que novos desafios são lançados para os profissionais docentes atuantes na EI, em especial para "garantir à criança acesso a processos de apropriação, renovação e articulação de conhecimentos e aprendizagens de diferentes linguagens [...]" (BRASIL, 2009, p. 18).

No contexto do direito à educação das crianças pequenas, análises assinalam uma adaptação da EI “[...] às leis do mercado e da concepção neoliberal, em que o ser humano é visto como capital e dele se espera retorno no investimento educacional, através da sua adaptação à nova estrutura social globalizada" (BONETTI, 2005, p. 61). Observa-se a constituição de um quadro social em que a EI se apresenta na pauta das discussões educacionais, integrando progressivamente os sistemas de ensino (vinda dos setores de assistência social) e, com isso, dialogando mais aproximadamente com as lógicas do modelo escolar.

Nesse movimento de gerar pertencimento ao sistema educacional e mobilizar discussões e análises próprias a sua dinâmica de funcionamento (que, muitas vezes, rivalizam com o modelo escolar), observa-se que a EI, embora tenha avançado em reconhecimento social, ainda não conquistou igual valorização de outras etapas e níveis de ensino. Esse quadro tem implicações nas profissionalidades requeridas por esse campo, ecoando nos indicativos apontados para os processos de formação, as dinâmicas de atuação e as políticas de reconhecimento e valorização que, por sua vez, compõem os níveis de atratividade desse campo profissional.

O campo profissional docente na EI vem historicamente questionando as lógicas de desvalorização e agenciando discussões sobre a profissionalidade em associação 
com o processo formativo requerido e estimulado nas políticas públicas (CÔCO, 2011). Cabe observar que o desenvolvimento profissional se articula às políticas de profissionalização, diretamente ligadas às regulações da formação inicial e continuada proposta aos docentes. Cabe observar, ainda, que a profissionalização no campo da EI se desenvolve também num diálogo permanente com a luta pelo reconhecimento do caráter educativo dessa etapa educacional. Numa reciprocidade, essa luta de reconhecimento da EI não pode perder de vista os requisitos de formação e as condições de trabalho oferecidas aos profissionais, no bojo do fortalecimento do conjunto do campo da EI.

Nesse processo de negociação, implicado com a constituição de pertencimento da EI aos sistemas de ensino, a configuração do trabalho docente geralmente vem sendo articulada com categorias distintas de profissionais, reunindo professores e auxiliares no trabalho direto com as crianças. Essa reunião de profissionais tem implicado uma hierarquização das ações educativas, repercutindo nas formas de atendimento às crianças e na configuração das profissões. Produz-se uma ideia de que os professores são responsáveis pelas ações vinculadas ao educar, apoiados pelos auxiliares que se responsabilizam pelas ações de cuidado, desconsiderando a premissa da indissociabilidade dessas ações no trabalho educativo com as crianças pequenas (CORSINO; NUNES, 2010; SCRAMIGNON, 2011). Ferreira e Côco (2011) apontam que "tal dinâmica pode ser observada nas novas políticas de contratação dos trabalhadores docentes e de fragmentação e flexibilidade do plano de carreira desses trabalhadores" (p. 362).

Os dados do Censo Escolar de 2009 informam a presença de 95.630 auxiliares na EI, dos quais 13,24\% atuam sem escolaridade de Ensino Médio (NUNES; CORSINO; DIDONET, 2011, p. 89). Geralmente, essa categoria profissional está mais presente na faixa da creche (crianças de 0 a 3 anos de idade) e, por não integrar a mesma carreira docente, configura-se como carreira paralela à de professor da EI (SILLER; CÔCO, 2008).

Com isso, assinalamos as fragilidades que envolvem o trabalho docente na primeira etapa da Educação Básica. Essas fragilidades evidenciam as desarticulações existentes entre as políticas de profissionalização dos docentes, delineadas pelo viés economicista (OLIVEIRA, 2004), e as funções sociopolíticas e pedagógicas da EI (BRASIL, 2010). As discussões dos quadros profissionais envolvem duas questões centrais: a formação requerida e o quantitativo de adultos necessários ao atendimento dos respectivos grupos que integram a faixa etária de atendimento da EI ( 0 a 6 anos). Focalizando a faixa etária correspondente à creche ( 0 a 3 anos), a composição dos quadros funcionais tem sido apresentada com base na proporção 
de um adulto (com expectativa de que seja um professor) para um quantitativo de seis a oito crianças. Para a ampliação do número de crianças atendidas por grupos (salas de atendimento), as políticas públicas vêm informando uma estratégia de compor uma atuação associando o professor e o auxiliar. Esta estratégia garante a presença de um professor por turma, mas, ao ampliar o número de crianças atendidas na turma, o segundo profissional designado geralmente não é outro professor. Desse modo, conforme assinalamos, para dar conta da expansão do atendimento na EI, compõem-se grupos profissionais distintos, com requisitos formativos diferenciados, implicados em condições de trabalho e valorização desiguais.

Avançando nessa temática das distinções entre profissionais docentes que atuam com o mesmo grupo de crianças na faixa da creche, a partir de pesquisa de abordagem qualitativa de orientação sócio-histórica (FREITAS, 2007), sustentada em referências bakhtinianas (BAKHTIN, 2003), focalizamos os sentidos circulantes no trabalho docente na EI. Consideramos que os processos interativos dialógicos, envolvidos numa perspectiva polifônica, favorecem a aproximação aos sentidos que emergem e circulam no trabalho docente na EI. Sentidos produzidos nas relações entre os sujeitos de um determinado contexto, no caso do estudo, nas interações entre as professoras e as auxiliares de creche no contexto institucional do desenvolvimento do seu trabalho, a saber, um Centro Municipal de Educação Infantil (CMEI). Para a aproximação aos sentidos circulantes sobre o trabalho docente na EI, foram desenvolvidos procedimentos metodológicos de observação participante e entrevistas, que possibilitaram captar, na interação com as enunciações dos sujeitos, sentidos de angústias, frustrações, dilemas e perspectivas no exercício de suas funções docentes com as crianças na EI. Assim, no bojo do desenvolvimento das políticas educacionais, indagamos a constituição do trabalho docente entre professoras e auxiliares de creche que atuam com o mesmo grupo de crianças na EI.

Nesse sentido, o artigo avança para a apresentação da abordagem teórico-metodológica adotada na pesquisa, que fornece os dados para essas reflexões. Posteriormente, desenvolve análises sobre a constituição do trabalho docente na EI, sustentadas nas enunciações dos sujeitos em especial, destacando dados de uma roda de conversa que reuniu seis auxiliares de creche e nove professoras. Por fim, tece algumas considerações finais evidenciando uma complexidade de atuação nesse campo de trabalho, que interroga as políticas públicas para a EI.

\section{A Pesquisa no contexto dialógico da docência na EI}

$\mathrm{Na}$ aproximação aos universos da EI, o foco no exercício do trabalho nesse campo requer uma compreensão de docência que abarca os distintos profissionais 
que diretamente se vinculam ao atendimento das crianças. Com referências bakhtinianas, assinalamos que essa compreensão de docência permite considerar que as tramas relacionais podem ser movidas com as lógicas decorrentes das especificidades de cada grupo profissional, que interagem com a dinâmica interna da instituição e não se apartam das negociações sociais mais ampliadas. Assim, a constituição do trabalho docente na EI está imbricada com a trama interativa dialógica da própria vida humana (BAKHTIN, 2011), com a relação com o outro, com a "confusão entre palavra sua e palavra do outro" (PONZIO, 2011, p. 244), compondo processos formativos por meio de um diálogo social, sempre inconcluso (BAKHTIN, 2011). Focalizamos os processos dialógicos tecidos no encontro entre os sujeitos docentes no contexto educativo, "independente da iniciativa do eu levar em consideração o outro, dirigir-se a ele e conceder-lhe a palavra" (PONZIO, 2011, p. 244). Enfim, tomamos a complexidade do viver a institucionalidade do trabalho docente na EI, integrado ao contexto coletivo de negociação da vida social.

Com esse arcabouço epistemológico, desenvolvemos a pesquisa com abordagem qualitativa, no intuito de compreender os sujeitos para, "com eles, compreender o contexto" (BOGDAN; BIKLEN, 1994, p. 27). Com a orientação sócio-histórica (FREITAS, 2007), movemos uma observação de que o homem "[...] nunca coincide consigo mesmo. [...] A vida autêntica do indivíduo só é acessível a um enfoque dialógico, diante do qual ele responde por si mesmo" (BAKHTIN, 2011, p. 67). Assim, auscultar (BAKHTIN, 2011) as palavras do(s) outro(s) na relação pesquisador-sujeito, de modo a considerar o "seu fazer, o seu ofício, a sua atitude, a sua prerrogativa, o seu peculiar modo de ser" (PONZIO, 2011, p. 252), tornou-se imprescindível aos propósitos estabelecidos de dialogar com as vozes que emergem no trabalho docente na EI.

A perspectiva de conhecer os sentidos que emergem dos sujeitos nos processos interativos dialógicos, vivificados na concretude do trabalho cotidiano com as crianças pequenas, exigiu a imersão nos grupos para apreender a constituição dos encontros (BAKHTIN, 2003) de forma situada e datada. Assim, a pesquisa teve como lócus uma instituição de EI da rede pública de um município da região Centro-Oeste Serrana do Estado do Espírito Santo, envolvendo um grupo de seis auxiliares de creche e nove professoras, totalizando quinze sujeitos participantes. Continuando esse detalhamento da pesquisa, apresentamos o perfil dos interlocutores e, em seguida, os procedimentos realizados no campo de estudo.

Os dados relativos ao perfil do grupo indicam a predominância exclusiva do sexo feminino. Em razão deste dado, passamos a priorizar o uso do feminino 
para retratar os dados referentes às profissionais. Em relação a raça/cor, estão distribuídas entre brancas (33,3\%), pardas (53,3\%) e negras $(13,3 \%)$. Os dados etários se distribuem nas faixas de 20 a 30 anos (13,3\%), de 31 a 40 anos (66,6\%) e de 51 a 60 anos $(20 \%)$, indicando que as profissionais de nossa pesquisa, em sua maioria, se encontram na faixa etária de 31 a 40 anos. Em termos de estado civil, há o maior indicador de casadas $(66,6 \%)$, tendo também solteiras (20\%) e divorciadas (13,3\%). Relativamente ao nível de escolaridade, encontramos uma composição com Ensino Médio (13,3\%), cursando nível superior (20\%) e especialização $(66,6 \%)$.

Em relação ao tipo de vínculo de trabalho, há indicadores de estatutário (66,6\%) e de designação temporária (33,3\%). No que diz respeito ao tempo de atuação na educação como profissional docente, temos a temporalidade de menos de um ano de atuação docente $(2,6 \%)$, o que podemos caracterizar como profissional iniciante no magistério, de um a dez anos de atuação docente (60\%) e de mais de dez anos a doze anos de atuação docente (33,3\%).

De maneira geral, esse perfil não se distancia dos outros indicadores apresentados em outras pesquisas no campo educacional brasileiro (GATTI; BARRETO, 2009; OLIVEIRA; VIEIRA, 2010). No escopo de focalização dos grupos profissionais na EI, destacamos os dados relativos à formação, formas de vinculação e experiência profissional, como elementos integrantes das distinções decorrentes do pertencimento a esse contexto. Nas características próprias do contexto investigado, assumimos o estudo como uma atitude responsável (BAKTHTIN, 2011), na dimensão ética do evento de integrar o encontro dialógico com os sujeitos. Nessa arena onde se confrontam múltiplos discursos (AMORIM, 2007), reconhecemos o outro do nosso lugar singular, exercendo a alteridade na tarefa de tentar captar algo do modo como os sujeitos se veem, com uma compreensão responsiva, mediante um olhar exotópico (BAKHTIN, 2003; AMORIM, 2007). Articulamos esse propósito aos princípios éticos indicados por Bogdan e Biklen (1994), de modo a atentar para a proteção à identidade dos sujeitos, agindo com clareza, ao negociar a autorização e encaminhar o estudo. Cabe destacar a utilização de pseudônimos escolhidos pelas profissionais com vistas a, simultaneamente, proteger a identificação e favorecer o reconhecimento pessoal nos dizeres visibilizados na pesquisa.

A imersão no campo ocorreu entre julho e dezembro de 2013, em dois movimentos distintos: observação participante na concretude da atuação docente com os pares de trabalho e participação nos processos formativos no coletivo (rodas de conversa) que aconteciam quinzenalmente (com um projeto de formação continuada), após a jornada de trabalho. 
Nas rodas de conversas, dialogamos sobre a constituição do trabalho docente na EI e, sobretudo, acerca da dinâmica profissional, estabelecida na parceria entre auxiliar de creche e professora. Desse modo, os dados registrados por meio do diário de campo (DC) e de gravações foram produzidos num clima interativo e cooperativo com os sujeitos participantes. Os diálogos foram mediados por temáticas relacionadas à docência na $\mathrm{EI}^{1}$, permitindo um aprofundamento das questões relacionadas à vivência profissional, tornando-se fundamental aos objetivos da pesquisa.

Também realizamos entrevistas individuais com cada sujeito participante. Esse encontro configurou-se como mais um momento intenso, pois as auxiliares de creche e professoras puderam expor suas inquietações, dilemas, frustrações, conquistas e alegrias em relação à sua atuação e às parcerias movidas no exercício do trabalho docente na EI.

Do conjunto de dados reunidos, para essa abordagem destacamos enunciações decorrentes de uma roda de conversa sobre as atribuições do trabalho docente na EI. Essa roda de conversa moveu a temática "atribuições docentes", agregando o estudo da legislação municipal referente ao cargo de auxiliares de creche e de professores, que constituem o trabalho docente na EI no contexto pesquisado. A dinâmica implicou uma organização do estudo com dois grupos distintos: um com as auxiliares de creche e outro com as professoras, em razão de a legislação informar tópicos próprios a cada função.

Nessa etapa, acompanhamos as profissionais auxiliares na incursão ao documento legal, na parte sistematizadora de suas atribuições. Para o cargo de auxiliar de creche, a lei descreve sumariamente as atribuições de:

Prestar apoio e participar do planejamento, execução e avaliação das atividades sociopedagógicas e contribuir para o oferecimento de espaço físico e de convivência adequados à segurança, ao desenvolvimento, ao bem-estar social, físico e emocional das crianças nas dependências das unidades de atendimento da rede municipal ou nas adjacências (Afonso Cláudio, 2006, art. 1, parágrafo $1 \mathrm{~s} / \mathrm{p}$.).

No detalhamento dessas atribuições, explicita as seguintes exigências:

Manter-se atualizado quanto às modernas técnicas profissionais; Requisitar e manter o suprimento necessário à realização das atividades;

\footnotetext{
No trabalho de campo, destacaram-se temáticas vinculadas à indissociabilidade do educar e cuidar; aos saberes-fazeres da El; à alimentação e banho; às crianças como sujeitos de direitos; aos eixos do trabalho vinculados às interações e brincadeiras; à avaliação das crianças e às normativas sobre as atribuições das funções docentes.
} 
Zelar pela higiene e limpeza do ambiente e dependências sob sua guarda; Observar as condições de funcionamento dos equipamentos, instrumentos e bens patrimoniais, solicitando os reparos necessários, para evitar riscos e prejuízos; Utilizar com racionalidade e economicidade e conservar os equipamentos, materiais de consumo e pedagógicos pertinentes ao trabalho; Observar regras de segurança no atendimento às crianças e na utilização de materiais, equipamentos e instrumentos durante o desenvolvimento das rotinas diárias; Acompanhar e participar sistematicamente dos cuidados essenciais referentes à alimentação, higiene pessoal, educação, cultura, recreação e lazer das crianças; Participar de programas de capacitação co-responsável; Participar em conjunto com o educador do planejamento, da execução e da avaliação das atividades propostas às crianças; Participar da execução das rotinas diárias, de acordo com a orientação técnica do educador; Colaborar e assistir permanentemente o educador no processo de desenvolvimento das atividades técnico-pedagógicas; Receber e acatar criteriosamente a orientação e as recomendações do educador no trato e atendimento à clientela; Auxiliar o educador quanto à observação de registros e avaliação do comportamento e desenvolvimento infantil; Participar juntamente com o educador das reuniões com pais e responsáveis; Disponibilizar e preparar os materiais pedagógicos a serem utilizados nas atividades; Auxiliar nas atividades de recuperação da auto-estima, dos valores e da afetividade; Observar as alterações físicas e de comportamento, desestimulando a agressividade; Estimular a independência, educar e reeducar quanto aos hábitos alimentares, bem como controlar a ingestão de líquidos e alimentos variados; Responsabilizar-se pela alimentação direta das crianças dos berçários; Cuidar da higiene e do asseio das crianças sob sua responsabilidade; Dominar noções primárias de saúde; Ajudar nas terapias ocupacionais e físicas, aplicando cuidados especiais com deficientes e dependentes; Acompanhar a clientela em atividades sociais e culturais programadas pela unidade; Auxiliar no recolhimento e entrega das crianças, inclusive as que fazem uso do transporte escolar, acompanhando-as na entrada e saída do mesmo, zelando assim pela sua segurança; Executar outros encargos semelhantes, pertinentes à função (Afonso Cláudio, 2006, art. 2, parágrafo 1, s/p.).

À medida que avançava a leitura do documento, um conjunto de manifestações se evidenciava, tais como: "As pessoas que fizeram essa lei não conhecem o nosso terreno" e "Tenho vontade de rasgar esse documento em cem pedaços" (DC, 11/11/2013). 
Com a pesquisa, assinalamos que esse espaço de diálogo possibilita aos sujeitos amplificar suas vozes, compondo coletivamente mais uma vivência formativa (BRAGANÇA, 2009). O espaço-tempo do CMEI é um lugar que constitui as ações inerentes ao atendimento às crianças e também de formação continuada, movendo, por vários (des)caminhos, o desenvolvimento profissional que não se produz descolado das funções e atribuições solicitadas aos profissionais e da negociação social relativa aos campos de trabalho.

Explicitado o delineamento metodológico empreendido, seguimos explorando as vivências comuns entre as profissionais no cotidiano do trabalho na EI.

\section{As vivências entre as profissionais docentes da EI}

Conforme viemos assinalando, o trabalho docente na EI, no encontro entre a professora e a auxiliar de creche que atuam com o mesmo grupo de crianças, é constituído de interações dialógicas que têm como referência legal a perspectiva pedagógica da indissociabilidade do educar e cuidar (BRASIL, 2010). Todavia, essa perspectiva é confrontada com iniciativas de designar profissionais próprios a cada uma dessas dimensões do trabalho educativo na EI. Assim, encontramos, conforme já problematizado na literatura do campo (CÔCO; SILLER, 2007; SCRAMIGNON, 2011; SOUZA, 2012), uma situação funcional díspar existente entre essas profissionais. Chegamos a essa observação captando um repertório hierárquico oficial definido por atribuições, carreira profissional, salário, carga horária de trabalho e formação.

Com a intenção de sublinhar esse repertório que materializa uma situação funcional díspar, exploramos os sentidos que emergiram do encontro entre as docentes, por meio da roda de conversa, ao revisitarem as legislações que normatizam seus cargos e funções.

Na composição da polifonia das vozes, afloraram divergências e ambiguidades sobre o entendimento de suas atribuições funcionais:

Beatriz: $O$ documento diz que as professoras mandam na gente e nós temos que ficar quietas. Aqui dentro isso não acontece, mas a lei é clara.

Larissa: Nós temos que limpar DVD, armários. Isso não tem condições, é um absurdo.

Laura: Temos que limpar os tatames, arrumar os berços e ainda cuidar das crianças... é sério... (Risos) 
Larissa: No CMEI onde trabalhei o ano passado, eu levava as crianças para o pátio e a minha auxiliar limpava a sala. Uma vez por semana ela faxinava tudo. Não tinha separação entre limpar e cuidar.

Beatriz: A limpeza da escola toda é de nossa responsabilidade.

Tânia: É muito dinheiro para fazer duas funções (Risos). Ser serviçal e auxiliar (Risos). Onde estão as horas do planejamento? Nós não ganhamos para planejar.

Uma professora canta para as auxiliares: lê, lê, lê, lê.... (DC, 11/11/2013).

Na dialogia, emergem novas observações sobre a situação das atribuições, no exercício compartilhado das funções docentes:

Rubia: Esse documento dá um poder para o professor, mas na lei do professor não está claro, não é delegada essa função. Essas leis estão desintegradas. Agora, se eu começar a achar que estou acima da Beatriz, o trabalho não vai render. Se for assim, a Beatriz vai achar que só deve fazer aquilo que está reservado a ela. Tem dia que não tem como (DC, 11/11/2013).

No exercício de estar com o outro na concretude do trabalho, a análise da demanda pelo envolvimento nos planejamentos assinala o modo como se configura determinadas relações entre as professoras e auxiliares:

Luana: Perante o que está escrito nas nossas funções eu só posso ser uma figura, simplesmente de corpo presente, sem poder falar. Eu só vou buscar os materiais, olhar as crianças e quem fala é a professora. É contraditório. Esses planejamentos servem para quê? O auxiliar é colaborador, pelo que está dentro das funções. Não tem como a gente ver o professor dando aula e não dar pitaco (DC, 11/11/2013).

Esses diálogos evidenciam que as auxiliares de creche não concordam com as funções postas nos documentos sobre suas atribuições. Assim, ao falarem sobre as atribuições de limpeza do espaço do CMEI e sobre o planejamento para o qual não são remuneradas, informam sentidos de insatisfações. Com isso, levantam provocações a respeito do trabalho docente na EI, no exercício profissional que reúne funções distintas, mas que precisam responder à complexidade das demandas das instituições que geralmente não se organizam conforme essas distinções. 
Sendo assim, acenamos uma rivalização entre o saber-fazer docente que se efetiva na concretude do encontro com as crianças e o documento oficial, que busca regular as atribuições do trabalho. Cabe observar que a complexidade do trabalho incide em dificuldades na demarcação de territórios funcionais. Também parece ser difícil considerar uma coordenação das ações de forma unilateral, somente pela função de professor. Essa fragilidade da fronteira funcional que existe no encontro entre professora e auxiliar de creche, de outro ângulo de análise, pode revelar a força da aproximação requerida ao exercício de suas funções com as crianças. Ainda os dados assinalam que também no interior de cada função se vivencia uma demarcação muito tênue das atribuições.

Nesse sentido, a professora Marina, ao apresentar na roda de conversa as funções dos docentes, por meio da leitura da legislação municipal associada, usa sua voz para complementar as variadas funções presentes no exercício do trabalho, indicando que as fronteiras não podem ser demarcadas. Ela lê "Desempenhar outras funções" e completa "ser psicóloga, ser assistente social, ser pai, ser mãe" (DC, 11/11/2013).

Assim, o trabalho docente na EI se apresenta revestido de uma complexidade que envolve "uma abrangência de tarefas e uma rede de interações alargadas" (OLIVEIRA-FORMOSINHO, 2002, p. 61). No exercício simultâneo compondo pares de trabalho com os cargos auxiliar de creche e professora, assinalamos que as assimetrias no reconhecimento e valorização desses cargos desfavorecem a produção de condições para a qualificação do trabalho coletivo (BRASIL, 2010). Em meio às (des)articulações, destacamos que essa complexidade envolve uma especificidade ligada à particularidade da execução do trabalho com crianças de 0 a 3 anos de idade que não pode ser apartada das discussões sobre a formação e reconhecimento do conjunto dos trabalhadores do campo educativo, no bojo das disputas por investimentos para o desenvolvimento da educação (CÔCO, 2012).

Nas diferenciações, o rendimento salarial se apresenta como um dos distintivos de diferenciação. Em 2013, o salário das professoras, para atuar em carga horária de 25 horas semanais, girava em torno de dois a três salários mínimos, considerando a categoria funcional na progressão horizontal ${ }^{2} \mathrm{e} \mathrm{vertical}^{3}$ na carreira, por meio do plano de cargos e salários do magistério.

\footnotetext{
2 Progressão horizontal se refere à passagem dos profissionais da educação de um nível de habilitação para outro superior, na mesma classe.

3 Progressão vertical se refere à elevação do profissional da educação ocupante de cargo de provimento efetivo à referência imediatamente superior dentro do nível a que pertence.
} 
Já os honorários das auxiliares de creche correspondem a um salário mínimo para uma carga horária de 40 horas semanais. Cabe destacar também que esse cargo não é integrado ao plano de cargos e salários do magistério público municipal. Desse modo, as auxiliares não contam com progressão profissional unificada aos quadros do magistério. As implicações dessas diferenças foram evidenciadas na voz de uma auxiliar de creche, ao discorrer sobre o que pensa acerca de seu salário, quando entrevistada:

Tem dia que eu não consigo parar de pensar sobre o meu salário. Foi frustrante quando fiz a somatória, recebo $R \$ 2,82$ por hora trabalhada. Não tenho um salário digno com a função que exerço (Graciosa, auxiliar de creche).

Nas vozes das outras auxiliares de creche emergem os sentidos da desvalorização salarial, ecoando numa compreensão de desvalorização da sua profissão que, por sua vez, é cotejada com a função de professora. Nesse cotejamento, reconhecem exercer uma função similar à da professora com o grupo de crianças:

Eu não concordo com o meu salário, deveria ser revisto. Um trabalho que deveria ser valorizado. Fazemos com responsabilidade, nos dedicamos mesmo ao que fazemos, não fazemos por fazer. $O$ valor financeiro que recebemos não condiz com a profissão (Luana, auxiliar de creche).

Ganhamos pouco pelo que fazemos (Beatriz, auxiliar de creche).

O descontentamento salarial das auxiliares move uma insatisfação que se endereça, além dos valores recebidos, aos elementos associados, implicados na ideia de uma falta de reconhecimento da importância de suas funções para o desenvolvimento da EI. Ao analisarem o processo de pertencimento a esse campo, indicam que a falta de oportunidades ou mesmo as opções de trabalho as levam a habitar esse "lugar" da EI. Ao ocuparem esses espaços, vão ao encontro do desenvolvimento de uma labuta mais complexa do que as atribuições postas ao cargo nas normativas legais.

Na dialogia com as professoras, se uma distância se efetiva como comparativo entre os valores recebidos, uma aproximação é nutrida por meio da vivência comum de insatisfação. As professoras, quando indagadas nas entrevistas sobre o que pensam a respeito de seu salário, mesmo ocupando um "lugar" diferenciado em relação às auxiliares, somam-se a essas na insatisfação. Informam que precisam ampliar a jornada de trabalho para ter um maior rendimento salarial. Afirmaram: 
Não estou satisfeita com meu salário, deveria ser maior para eu trabalhar em um horário somente (Cláudia, professora).

Sou dependente do meu salário, mas poderia ser melhor (Marina, professora).

Penso que deveria ser mais valorizado, para podermos trabalhar somente um horário, dando mais atenção às propostas de trabalho (Maria Antonia, professora).

Poderia ser melhor, para investimento em formação (Rúbia, professora).

Não estou satisfeita, tem que melhorar, mas não é tão ruim comparado a outras profissões (Maria Antonieta, professora).

$\mathrm{Na}$ ausculta dessas vozes, analisamos que as insatisfações diante das condições salariais, ainda que comuns entre as auxiliares de creche e professoras, não se assemelham, em especial, porque são tecidas no bojo de diferenciações no contrato de trabalho. Se as professoras somam coro nos quadros do magistério, é importante observar que o cargo da auxiliar de creche não está integrado à carreira do magistério, intensificando as lógicas de precarização do trabalho docente (CÔCO, 2010).

Um segundo distintivo se refere à carga horária de trabalho. É evidente nas enunciações das auxiliares de creche o peso das oito horas de trabalho diário, compondo uma carga horária semanal de 40 horas.

As professoras, no bojo da luta por melhores condições de trabalho, consideram a carga horária de cinco horas de trabalho diário suficiente, até porque vivem uma dialogia com as auxiliares que trabalham oito horas diárias. Todavia, ressaltam a importância de investimento para que possam atuar somente em um turno, de os planejamentos estarem encaixados no horário de trabalho e de, muito especialmente, lograrem melhor valorização salarial.

Nesse contexto, a formação inicial se apresenta como mais um distintivo entre as profissionais. Nas normativas locais, a formação exigida para atuar como docente é graduação em pedagogia e ou normal superior, acrescida de curso de berçarista ou similar com carga horária mínima de 80 horas. Para a atuação como auxiliar de creche, a formação exigida é Ensino Fundamental completo, também acrescida de curso de berçarista ou similar com carga horária mínima de 80 horas/aula, sem exigência de experiência profissional anterior. 
Assim, em virtude da formação inicial exigida, verifica-se a composição de dois perfis profissionais muito distintos, ligados pela participação em curso de berçaristas. Essas diferenças na composição do quadro de profissionais se mostram relevantes justamente por se vincularem a um trabalho que envolve um projeto pedagógico que "consiste em perseguir objetivos, ao mesmo tempo, de socialização e de instrução" (TARDIF, 2011, p. 196) com as crianças. Portanto, requerer investimentos coletivos, em condições muito desiguais, pode não ganhar a organicidade necessária.

Neste quadro, as enunciações das auxiliares de creche entrevistadas expressam os sentidos de sua atuação-vivência nessa profissão, apontando uma memória de futuro que calcula seus horizontes de possibilidades (BAKHTIN, 2003; GERALDI, 2010), no inacabamento da constituição profissional:

Pretendo atuar como professora. Não sou apaixonada, eu amo atuar na EI. Paixão passa amor não. Não tem diferença do trabalho do professor, da mesma forma que o professor atua eu também atuo, não tem diferença entre o professor e auxiliar. Sabemos que tem pessoas que diferenciam o auxiliar, até mesmo dentro do CMEI, olham com indiferença para gente. Não tem diferença entre nossa atuação no ambiente direto do trabalho. Já tem cinco anos que atuo como auxiliar e não vejo diferença no trabalho (Luana, auxiliar de creche).

Eu atuo como auxiliar, não quero isso para o resto da minha vida (Laura, auxiliar de creche).

Eu gosto muito! Eu não desenvolvo somente a minha profissão de auxiliar como é para ser seguida, para dar banho ou seguir outras ordens. Desenvolvo junto com a professora, faço os planejamentos com elas, dou continuidade às atividades propostas. Quando as professoras faltam, eu tenho um plano de aula, mesmo que seja simples (Beatriz, auxiliar de creche).

Eu quero aprender mais, estou estudando para melhorar meu salário, quero ser pedagoga. Como auxiliar de creche eu não tenho perspectiva de progressão (Lívia, auxiliar de creche).

Na medida em que eu conseguir outro trabalho, eu mudo (Tânia, auxiliar de creche). 
Eu quero voltar pra sala de aula, eu gosto da alfabetização. Tenho o desejo. Há um desestímulo, nessa situação não tem melhora. O governo quer mão de obra qualificada e barata (Graciosa, auxiliar de creche).

Nesses diálogos, emergiram os sentidos de ocupar um "lugar" profissional observado como não valorizado, acenando vários movimentos ligados às permanências e mudanças que se mostram possíveis. Podemos apreender vários sentidos intercambiantes ao trabalho em curso: o "amor pela EF", a "busca pelo conhecimento" e "o intenso desejo em atuar como professora, pedagoga ou mesmo em outra profissão". Com os dados, aventamos que as auxiliares constituem seu trabalho compondo um lugar de passagem nessa função, de modo a projetar melhores condições de vivência em outro lugar profissional e, assim, produzir outros pertencimentos.

Por outro lado, na multiplicidade dos sentidos vivenciados nessa profissão, percebemos nas professoras uma lógica de mais pertencimento não manifestando o desejo de sair do magistério. Nas enunciações "gosto" e "amor" pela EI, desejo pela "busca do conhecimento" e das perspectivas de "dias melhores", ainda que a precariedade do trabalho seja destacada, capta-se um maior pertencimento:

Gosto muito mesmo, aprendi a gostar da profissão, me apaixonei (Maria Antonia, professora).

Nunca pensei em ser professora, agora eu não quero sair da EI. Não é valorizado, mas eu gosto de ser professora (Rúbia, professora).

Em termos de trabalho estou satisfeita, em parte. Tenho muito que crescer, tenho que construir muito para diferenciar (Maria Antonieta, professora).

Gosto do que faço. Gostaria de mais estudos aprofundados, que fossem oportunizados mais estudos pela SEMED da EI (Laila, professora).

Tenho necessidade de me aperfeiçoar, dedicar-me mais à profissão. Eu gosto de atuar como professora, só que falta recurso, está falho (Cláudia, professora).

Tenho perspectiva de dias melhores, temos que ter, mais diante das condições de trabalho, falta de material torna-se desmotivador, o salário é desanimador (Marina, professora). 
Esses sentidos de paixão ou gosto, expressos nas vozes aqui analisadas, "parecem justificar a falta de reconhecimento social, a inexistência de recursos financeiros ou de outros fatores em geral considerados válidos para escolher uma profissão ou permanecer nela" (NASCIMENTO et al., 2005, p. 49). Com a professora Bárbara, assinalamos que esse sentido do "amor" pelo exercício docente, ainda que tome destaque, não pode invisibilizar suas insatisfações e dificuldades trabalho cotidiano.

Eu sonhava em ser professora desde criança, eu faço por amor. Eu amo a minha profissão, amo a minha escola. Mas, durante esse ano eu tive vontade de sair daqui, estou sobrecarregada, insatisfeita com todos os problemas vivenciados com as auxiliares. Nunca, ninguém (direção) me procurou para saber como estava acontecendo o trabalho. Eu tive vontade de falar com a direção, mas tive vergonha. Eu sei que não sou perfeita (Bárbara, professora).

Um trabalho que vivencia lógicas de desvalorização que se, por um lado, afeta a todos (professores e auxiliares), por outro, mostra também implicações muito distintas. Implicações para os sujeitos e também para a configuração institucional. Nesse contexto, com os dados indicamos muitas afinações e parcerias e também muitas dificuldades e conflitos na vida comum com as crianças. Na complexidade do trabalho, parece muito difícil delimitar as fronteiras do que é a tarefa de cada um e do que é tarefa comum a todos, ainda que as prescrições enumerem detalhadamente as atribuições. Talvez o exercício do trabalho esteja provocando a indagação se é mesmo necessário e/ou possível demarcar as fronteiras, explodindo - não sem tensões - as lógicas hierarquizantes impostas. De todo modo, não podemos desconsiderar que esses dados também assinalam que essa dinâmica de trabalho docente, com categorias distintas, reverbera nas práticas pedagógicas, divisando o educar e o cuidar. Ao convivermos com o estabelecimento de funções próprias a cada cargo, vemos uma educação diluída em sua integralidade, fragilizando a proposição do trabalho coletivo da EI (BRASIL, 2010).

\section{Considerações Finais}

Neste texto, focalizamos a constituição do trabalho docente na EI, observando, especialmente, as vivências profissionais partilhadas entre auxiliares de creche e as professoras no cotidiano de um CMEI. Com os dados captados na pesquisa, evidenciamos a existência de distintivos profissionais, definidos por meio de um repertório hierárquico oficial, que confronta com as orientações para as ações educativas que afirmam a integralidade do processo educativo das crianças pequenas, reunindo as ações de cuidado e educação nas instituições de EI (BRASIL, 2010). 
Esse repertório é composto de distinções referentes a atribuições, carreira profissional, remuneração, carga horária e formação, colocando as profissionais docentes em uma situação funcional díspar, em meio ao desafio de encaminhar um trabalho articulado que possibilite vivenciar a indissociabilidade do educar e do cuidar. Com base em nossas análises, observamos que, ainda que parcerias sejam possíveis, almejadas e frutificadas, essa situação não favorece articulações entre os profissionais docentes da EI na "arena da prática" do trabalho (BALL, 2001).

As desarticulações são dimensionadas tanto na atuação docente da auxiliar de creche quanto na atuação da professora, ainda que o esforço de comunicabilidade no trabalho precise ser reconhecido. Sobre esse aspecto, a complexidade do trabalho docente reúne um conjunto de tensões que atravessam as dimensões de execução do trabalho com as crianças, dos sentidos de reconhecimento e valorização profissional evidenciados e dos investimentos no fortalecimento da EI como campo educativo.

Em resumo, os resultados obtidos permitem indicar que os elementos de desigualdade profissional encontrados na vivência conjunta da docência, cotejada com os objetivos de indissociabilidade do educar e do cuidar, não favorecem uma articulação entre as profissionais no exercício do trabalho na EI. Com isso, emerge a indagação sobre a possibilidade de construir projetos coletivos de trabalho e de gerar pertencimento a esse campo. Desse modo, é importante problematizar o engendramento das políticas públicas educativas que, revestidas de lógicas globais, incide no trabalho docente na EI, intensificando a precarização do trabalho docente.

Com base nos resultados, aventamos a necessidade de fortalecer os processos de valorização do trabalho docente no campo da EI. Ao participarmos da formação continuada com as professoras e as auxiliares, integramos os diálogos na vida comum do trabalho com crianças. No encontro com os dizeres circulantes, foi possível observar associações, choques, tensionamentos e muitas outras formas de fazer interagir os sentidos para as ações em curso na EI. Nessa dialogia e com destaque ao percurso de lutas do campo da EI, concluímos este artigo com a perspectiva de que é necessário continuar os estudos, aprofundar discussões sobre o tema e mobilizar novas iniciativas de ação que fortaleçam o campo da EI, em especial, focalizando a composição de seus quadros profissionais. 


\title{
Educational public policies: voices who emerges of docent work in childhood education
}

\begin{abstract}
This article, resulting from a master's degree research, addresses the public policy in early childhood education (ECE), focusing on the teaching in view of the statement of inseparability between educating and caring. It discusses the issue of the presence of different groups of teachers working with the same group of children. It is argued in the development of qualitative research of socio-historical orientation, with methodological procedures of participant observation and interviews. The data indicate, in the midst of the educational public policies, that the constitution of teaching in early childhood education interacts with an official hierarchical repertoire consisting of aspects related to required training, demanded attributes and delineation of the careers, with its recognition and valorization policies, weakening the prospect of the inseparability of education and care in this field.
\end{abstract}

Keywords: Early childhood education. Teachers. Educational public policies.

\section{Política pública educativa: voces emergentes en el trabajo docente en la educación infantil}

\section{Resumen}

En este artículo, derivado de la investigación de maestría, se aborda la politica pública en el campo de la Educación de la Primera Infancia (ECE), centrándose en la creación de la enseñanza en vista de la afirmación de la inseparabilidad de la educación y el cuidado. Discute la cuestión de la presencia de diferentes grupos de profesores profesionales que trabajan con el mismo grupo de niños. Sostenido en el desarrollo de la investigación cualitativa de orientación socio-histórica, con los procedimientos metodológicos de la observación participante y entrevistas. Los datos indican, en medio de las políticas educativas, que la constitución de la enseñanza en la IE interactúa con un repertorio jerárquico oficial y se compone de aspectos relativos a la formación necesaria, que las asignaciones de diseño exigieron de las carreras profesionales, con sus políticas de reconocimiento y aprecio, lo que debilita la perspectiva de la inseparabilidad de la educación y el cuidado en este campo.

Palabras clave: Educación de la primera infancia. Profesionales de la enseñanza. De educación política pública. 


\section{Referências}

AFONSO CLÁUDIO. Decreto-lei $n^{\circ} 1.715$, de 10 de março de 2006.

Regulamenta no âmbito municipal o Cargo Auxiliar de Creche da Prefeitura Municipal de Afonso Cláudio. Afonso Cláudio, 2006.

AMORIM, M. A contribuição de Mikhail Bakhtin: a tripla articulação ética, estética e epistemológica. In: FREITAS, M. T.; SOUZA, S. J.; KRAMER, S. (Org.). Ciências humanas e pesquisa: leituras de Mikhail Bakhtin. São Paulo: Cortez, 2007. p. 11-25.

BAKHTIN, M. M. Estética da criação verbal. 4. ed. São Paulo: Martins Fontes, 2003.

. Problemas da poética de Dostoiévski. 5. ed. Rio de Janeiro: Forense Universitária, 2011.

BALL, S. J. Diretrizes políticas globais e relações políticas locais em educação. Currículo sem Fronteiras, v. 1, n. 2, p. 99-116, jul. 2001. Disponível em: $<$ http://www.curriculosemfronteiras.org/volliss2articles/ball.pdf $>$. Acesso em: 10 jun. 2014.

BOGDAN, R. C.; BIKLEN, S. K. Investigação qualitativa em educação. Lisboa: Porto, 1994.

BONETTI, N. Lei de diretrizes e bases e suas implicações na formação de professores de educação infantil. In: MARTINS FILHO, A. J. (Org.). Criança pede respeito. Porto Alegre: Mediação, 2005. p. 109-47.

BRAGANÇA, I. F. S. O/a professor/a e os espelhos da pesquisa educacional. Revista Brasileira de Estudos Pedagógicos, Brasília, DF, v. 90, n. 224, p. 87-101, jan./abr. 2009. Disponível em $<$ http://rbep.inep.gov.br/index.php/RBEP/issue/ view/102/showToc>. Acesso em: 10 jun. 2014.

BRASIL. Ministério da Educação. Secretaria de Educação Básica. Coordenação de Educação Infantil. Política de educação infantil no Brasil: relatório de avaliação. Brasília, DF, 2009.

. Ministério da Educação. Secretaria de Educação Básica. Diretrizes curriculares nacionais para a educação infantil. Brasília, DF, 2010. 
CÔCO, V. A configuração do trabalho docente na educação infantil. In: CONGRESSO IBERO-LUSO BRASILEIRO DE POLÍTICA E ADMINISTRAÇÃO DA EDUCAÇÃO, 6., 2010, Elvas, Portugal. Anais... [S.1.]: Anpae, 2010. Disponível em: <http://www.anpae.org.br/ iberolusobrasileiro2010/cdrom/118.pdf>. Acesso em: 9 jun. 2013.

. Experiências de atuação docente na formação inicial. In:

SIMPÓSIO BRASILEIRO DE POLÍTICA E ADMINISTRAÇÃO DA EDUCAÇÃO, 25.; CONGRESSO IBERO-AMERICANO DE POLÍTICA E ADMINISTRAÇÃO DA EDUCAÇÃO, 2011, São Paulo, SP. Anais... São Paulo: ANPAE, 2011. p. 1-9. Disponível em: <http:// www.anpae.org.br/simposio2011/cdrom2011/PDFs/trabalhosCompletos/ comunicacoesRelatos/0527.pdf>. Acesso em: 12 nov. 2013.

. Trabalhador docente na educação infantil no Espírito Santo. In: BARTOLOZZI, E.; OLIVEIRA, D. A.; VIEIRA, L. F. O trabalho docente na educação básica: o Espírito Santo em questão. Belo Horizonte: Fino Traço, 2012. p. 59-80.

CORSINO, P.; NUNES, M. F. R. Políticas públicas universalistas e residualistas: os desafios da Educação Infantil. In: REUNIÃO DA ASSOCIAÇÃO NACIONAL DE PÓS-GRADUAÇÃO E PESQUISA EM EDUCAÇÃO, 33., 2010, Caxambu. Anais... Caxambu: Anped, 2010. Disponível em: <http://www.anped.org.br/33encontro/internas/trabalhos-gt07. pdf $>$. Acesso em: 20 fev. 2013.

FERREIRA, E. B.; CÔCO, V. Gestão na educação infantil e trabalho docente. Retratos da Escola, Brasília, DF, v. 5, n. 9, p. 357-69, jul./dez. 2011.

FREITAS, M. T. A perspectiva sócio-histórica: uma visão humana da construção do conhecimento. In: FREITAS, M. T.; SOUZA, S. J.; KRAMER, S. (Org.). Ciências humanas e pesquisa: leituras de Mikhail Bakhtin. São Paulo: Cortez, 2007. p. 12-26.

GATTI, B. A.; BARRETO, E. S. S. Professores do Brasil: impasses e desafios. Brasília, DF: Unesco, 2009. Disponível em: $<$ http://unesdoc.unesco.org/ images/0018/001846/184682por.pdf $>$. Acesso em: 10 jun. 2014.

GERALDI, J. W. Ancoragens: estudos bakhtinianos. São Carlos: Pedro \& João, 2010. 
NASCIMENTO, A. et al. Educar e cuidar: muito além da rima. In: KRAMER, S. (Org.). Profissionais de educação infantil: gestão e formação. São Paulo: Ática, 2005. p. 55-86.

NÓVOA, A. Os professores e as histórias da sua vida. In: . (Org.).

Vidas de professores. Lisboa: Porto, 2011. p. 11-30. (Ciências da Educação, 4).

NUNES, M. F. R.; CORSINO, P.; DIDONET, V. Educação infantil no Brasil: primeira etapa da educação básica. Brasília, DF: Unesco, 2011.

OLIVEIRA, D. A. A nova regulação de forças no interior da escola: carreira, formação e avaliação docente. Revista Brasileira de Política e Administração da Educação, Goiânia, v. 27, n. 1, p.25-38, jan./abr. 2011.

. Reformas educacionais na América Latina e os trabalhadores docentes. Belo Horizonte: Autêntica, 2004.

OLIVEIRA, D. A.; VIEIRA, L. M. F. (Coord.). Pesquisa "Trabalho docente na educação básica no Brasil: sinopse do survey nacional. Belo Horizonte: Universidade Federal de Minas Gerais, 2010.

OLIVEIRA-FORMOSINHO, J. A formação em contexto. In: OLIVEIRAFORMOSINHO, J.; KISHIMOTO, T. M. (Org.). Formação em contexto: uma estratégia de integração. São Paulo: Pioneira Thonson Learning, 2002. p. 1-40.

PONZIO, A. A revolução bakhtiniana: o pensamento de Bakhitn e a ideologia contemporânea. São Paulo: Contexto, 2011.

SCRAMIGNON, G. B. S. O lugar da creche na educação Infantil. In: REUNIÃO DA ASSOCIAÇÃO NACIONAL DE PÓS-GRADUAÇÃO E PESQUISA EM EDUCAÇÃO, 34., 2011, Natal. Anais... Natal: Anped, 2011. Disponível em: $<$ http://www. 34reuniao. anped.org.br/index/gt07.pdf $>$. Acesso em: 8 jan. 2013.

SILLER, R. R.; CÔCO, V. O ingresso de profissionais na educação infantil: o que indicam os editais dos concursos públicos. In: REUNIÃO DA ASSOCIAÇÃO NACIONAL DE PÓS-GRADUAÇÃO E PESQUISA EM EDUCAÇÃO, 31., 2008, Caxambu. Anais... Disponível em: <http://www. anped.org.br/reunioes/31ra/1 trabalho/GT07-4250--Int.pdf $>$. Acesso em: 14 out. 2012. 
SOUZA, M. P. C. O proinfantil e a formação dos agentes auxiliares de creche do município do Rio de Janeiro. In: REUNIÃO DA ASSOCIAÇÃO NACIONAL DE PÓS-GRADUAÇÃO E PESQUISA EM EDUCAÇÃO, 35. 2012, Porto de Galinhas. Anais... Porto de Galinhas: Anped, 2012. Disponível em: $<$ http://www.35reuniaoanped.org.br/index.php/images/trabalhos/GT08. pdf $>$. Acesso em: 8 dez. 2013.

TARDIF, M. Saberes docentes e formação profissional. 12. ed. Petrópolis: Vozes, 2011.

VICENTINI, P. P.; LUGLI, R. G. História da profissão docente no Brasil: representações em disputa. São Paulo: Cortez, 2009.

\section{Informações das autoras}

Verônica Belfi Roncetti Paulino: Mestrado em Educação, Programa de Pós-Graduação em Educação da Universidade Federal do Espírito Santo - PPGE/UFES. Integrante do Grupo de Pesquisa "Formação e Atuação de Educadores" - GRUFAE. Pedagoga vinculada à Secretaria Municipal de Educação da Prefeitura Municipal de Afonso Cláudio. Contato: veronicabelf@hotmail.com

Valdete Côco: Doutorado em Educação, Universidade Federal Fluminense - UFF. Professora - PPGE/CE/UFES. Coordenadora do Grupo de Pesquisa "Formação e Atuação de Educadores" - GRUFAE. Tutora do Programa de Educação Tutorial Conexões de Saberes: Projeto Educação. Contato: valdetecoco@hotmail.com 